\title{
EFEITO DE INSETICIDAS NÃO-NEUROTÓXICOS SOBRE OVOS, NINFAS E ADULTOS DE Euschistus heros (Fabricius, 1798)
}

\author{
Ronaldo Zantedeschi ${ }^{1}$ \\ Ciro P. G. Pinto ${ }^{2}$ \\ Aline C. Padilha ${ }^{3}$ \\ Bruna Piovesan ${ }^{4}$ \\ Gustavo S. Fialho ${ }^{5}$
}

Resumo: A cultura da soja é atacada por diversos insetos-praga, divididos principalmente em mastigadores e sugadores. O percevejo-marrom-da-soja (Euschistus heros) tem se destacado como uma das principais pragas sugadoras por causar danos, principalmente, no estágio reprodutivo da cultura. Neste trabalho objetivou-se avaliar o efeito de inseticidas utilizados para pragas mastigadoras da soja sobre ovos, ninfas e adultos de Euschistus heros. Foi avaliada a mortalidade de ovos, ninfas e adultos, além do efeito subletal sobre a fecundidade dos adultos. Foram realizados ao total 5 tratamentos, na máxima dosagem registrada para soja: tiametoxam+lambda-cialotrina, flubendiamida, diflubenzurom e lufenurom. Os resultados indicam que flubendiamida e lufenurom apresentaram efeito sobre ninfas de $E$. heros, apesar de serem utilizados apenas para o controle de lepidópteros. Além disso, os inseticidas testados não apresentaram efeitos negativos sobre ovos e na fecundidade das fêmeas.

Palavras-chave: Percevejo-marrom-da-soja, Regulador de crescimento, Rianodina.

\footnotetext{
${ }^{1}$ Programa de Pós-Graduação em Fitossanidade/ UFPel, Brasil. E-mail: ronaldozantedeschi@gmail.com. ${ }^{2}$ Programa de Pós-Graduação em Fitossanidade/ UFPel, Brasil. E-mail: pedrociro23@hotmail.com.

${ }^{3}$ Programa de Pós-Graduação em Fitossanidade/ UFPel, Brasil. E-mail: acostapadilha08@gmail.com. ${ }^{4}$ Programa de Pós-Graduação em Fitossanidade/ UFPel, Brasil. E-mail: bruna-piovesan@hotmail.com. ${ }^{5}$ Programa de Pós-Graduação em Fitossanidade/ UFPel, Brasil. E-mail: gsfialho@hotmail.com.
} 